\title{
Introduction to the Special Issue: Evaluating Assistive Technology in the Education of Persons with Severe Disabilities
}

\author{
Jeff Sigafoos
}

Published online: 22 February 2011

(C) Springer Science+Business Media, LLC 2011

\begin{abstract}
This special issue of the Journal of Behavioral Education was prepared to highlight the use of a range of assistive technologies for promoting improved learning and adaptive behavior functioning among individuals with severe disabilities. The range of technologies evaluated in this special issue includes microswitches, assistive communication devices, iPods, and computer-based technologies. Collectively, these papers illustrate how the use of assistive technology can be taught and evaluated to ascertain its effects on learning and adaptive functioning among person with severe disabilities.
\end{abstract}

Keywords Assistive technology $\cdot$ Evaluation - Severe disabilities

This special issue of the Journal of Behavioral Education focuses on evaluating the use of assistive technologies in educational programs for individuals with severe disabilities. For the purpose of this special issue, the term severe disability is used to refer to individuals with significant deficits in adaptive behavior functioning and significant learning and behavioral problems. Assistive technologies can help to mitigate the challenges that arise in attempting to increase participation and meet the educational and habilitative needs of individuals with severe disabilities.

This special issue is timely and important because new and more sophisticated technologies are emerging at a rapid rate. Educators have been quick to embrace such technologies, but individuals with severe disabilities are at risk for being denied access to this technology. While Lindsay and Tsybina (2011) noted that

\footnotetext{
J. Sigafoos $(\bowtie)$

School of Educational Psychology \& Pedagogy, Victoria University of Wellington,

PO Box 17-310, Karori, Wellington, New Zealand

e-mail: jeff.sigafoos@vuw.ac.nz
} 
access to technology is "essential for people with disabilities", they also noted "high rates of underutilization" (p. 10).

How might one explain the discrepancy between the essential need for technology on the one hand, but its underutilization on the other hand? Some might speculate that this is a cost issue. To be sure, some assistive technologies that might be essential for persons with severe disabilities could be prohibitively expensive, but most are not and most are commonly found in schools (e.g., computers, iPods, microswitches). A second possible reason could be a view that such individuals may be incapable of learning and uninterested in using such technologies. The results of the present series of papers refute this argument. Indeed, the papers in this special issue show quite convincingly that a range of assistive technologies can be successfully taught to individuals with severe disabilities. This is an important message.

But, I am sure the contributing authors are under no illusion that one merely has to procure the technology to watch its benefits unfold. Procurement is only half the story, perhaps, even less than half. Instead, as the papers in this special issue suggest, individuals with severe disabilities are likely to require explicit, deliberate, systematic, and often very intensive instruction to ensure that they do in fact learn to use, and benefit from, assistive technology. This systematic instruction is another, equally important, type of technology: a technology of teaching, so to speak, that has a long history in behavioral education. As far back as 1968, the psychologist B. F. Skinner argued that improvements in teaching would flow from embracing technology. He was in fact talking about two types of technology. One of these was a technology of teaching based on scientifically validated principles of learning. The other was the use of technology for teaching. Today, these technologies for teaching include computers, iPods, and microswitches. One might include here a third type of technology and that is a technology for evaluating the effects of teaching.

In the present context, evaluation technology aims to demonstrate whether the teaching procedures have in fact lead to successful technology use. The papers in this special issue provide a tremendous service to that end by showing precisely how to evaluate the effects of interventions to teach individuals to use various types of assistive technologies. So here in the pages of this special issue, we have demonstrations of how to use assistive technology to promote and enhance a range of important educational and more general therapeutic outcomes, specifically: (a) accessing stimulation (Lancioni et al.), (b) increasing communication (Ramdoss et al.; Schieltz et al.), (c) developing reading skills (Yaw et al.), and (d) prompting age-appropriate leisure skills (Kagohara). As it turns out, evaluative technologies used in these papers all involved the use of single-case experimental designs (Kennedy 2005), which is closely linked to behavioral education.

Readers will hopefully sense that the main contribution of this special issue is the strong evidence that behavioral education can in fact enable individuals with severe disabilities to use and benefit from a range of assistive technologies. This contribution will hopefully reduce the underutilization of assistive technology in educational programs for individuals with severe disabilities. I want to thank the authors for their important contributions and the Editor for providing the 
opportunity to disseminate this important message in the pages of the Journal of Behavioral Education.

\section{References}

Kennedy, C. H. (2005). Single-case designs for educational research. Boston: Allyn and Bacon.

Lindsay, S., \& Tsybina, I. (2011). Predictors of unmet needs for communication and mobility assistive devices among youth with a disability: The role of socio-cultural factors. Disability and Rehabilitation: Assistive Technology, 6, 10-21.

Skinner, B. F. (1968). The technology of teaching. Englewood Cliffs: Prentice-Hall. 